\title{
Cystic artery lymph node-is it a fixed important landmark during cholecystectomy?
}

\author{
Kor Woi Tiang ${ }^{1,2,3 *}$, Jia Xin Peng ${ }^{2}$ and Arkadiusz Peter Wysocki ${ }^{2}$ \\ ${ }^{1}$ Department of Surgery, Logan Hospital, Meadowbrook, Queensland, Australia \\ ${ }^{2}$ Griffith University, Brisbane, Queensland, Australia \\ ${ }^{3}$ University of Queensland, Brisbane, Queensland, Australia
}

\begin{abstract}
Bile duct injury during laparoscopic cholecystectomy (LC) is rare and often happens due to misidentification. Experts recommend dissection during laparoscopic cholecystectomy occur lateral to the cystic artery lymph node (LN). The $\mathrm{LN}$ is classically identified as a single node overlying the cystic artery and lateral to the bile duct. It thus represents another important landmark during LC. We present the first patient, to our knowledge, with 3 LNs in the hepatobiliary triangle. The laparoscopic cholecystectomy and recovery were uneventful. The LN is an important anatomical marker during $\mathrm{LC}$ and the presence of multiple LNs does not impact on surgical technique.
\end{abstract}

Abbreviations: BDI: Bile duct injury; LC: Laparoscopic cholecystectomy; LN: Cystic artery lymph node

\section{Introduction}

Cholecystectomy is one of the commonest major operations performed in Australia with more than $90 \%$ performed laparoscopically (LC) $[1,2]$. Major bile duct injury (BDI) represents one of the most feared complications in terms of morbidity and resource utilization. Experts recommend dissection during laparoscopic cholecystectomy occur lateral to the cystic artery lymph node (LN). The cystic artery lymph node, also known as Lund's Node and Mascagni's Node, is typically identified as a single node superficial to the cystic artery and lateral to the bile duct [3].

A recent paper reported the cystic artery $\mathrm{LN}$ was excised in $10.4 \%$ of 1332 consecutive LC by a single surgeon [4]. In that study the rate was independent of the majority of patient factors and degree of surgical difficulty [5]. However, that retrospective study hinged on the assumption that the LN is always solitary. We present a case of 3 cystic artery lymph nodes within the hepatobiliary triangle identified during laparoscopic cholecystectomy.

\section{Case presentation}

33-year old otherwise well woman underwent an elective laparoscopic cholecystectomy (LC) at a teaching hospital in Queensland, Australia (Figure 1). The indication for surgery was recurrent biliary colic. Abdominal ultrasound demonstrated several stones up to $15 \mathrm{~mm}$ diameter with no biliary dilatation. On the day of surgery, after routine capnoperitoneum and opening of the gallbladder peritoneum, three LNs were identified within hepatobiliary triangle. The LNs were well circumscribed and oval, had a maximum diameter of less than $5 \mathrm{~mm}$ and were situated superficial to the cystic artery. Intraoperative cholangiogram demonstrated intact hilar ductal anatomy with free flow of contrast into the duodenum. None of the nodes were excised. The operation was completed uneventfully, and the patient was discharged well the next morning. Histology showed an unopened gallbladder measuring $80 \times 33 \mathrm{~mm}$ with three yellow calculi measuring up to $17 \times 15 \times 15 \mathrm{~mm}$. Microscopic features were consistent with chronic cholecystitis. The patient had no known clinical cause such an infection or systemic disease to explain to presence of 3 LNs. Histological appearance of the lymph node was not described as these were not excised.

\section{Discussion}

Bile duct injury represents a serious surgical complication, as it often requires major reconstructive surgery. BDI is associated with

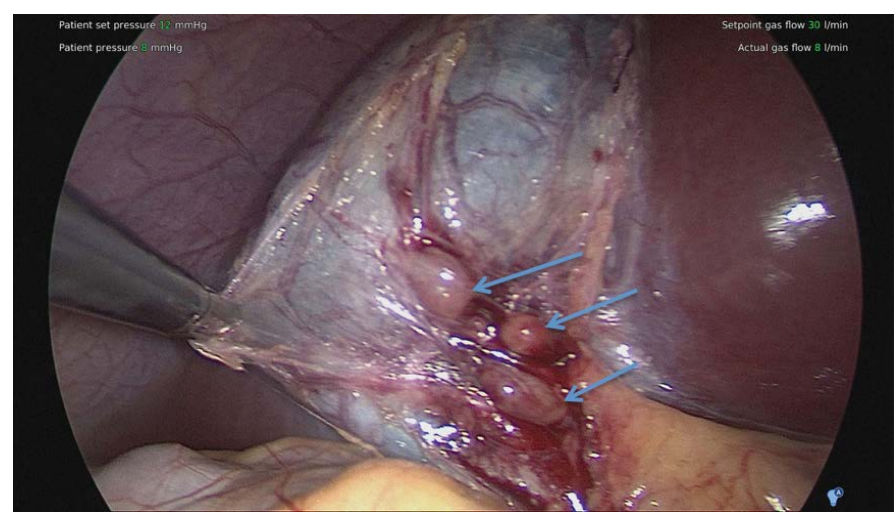

Figure 1. Blue arrows show Multiple Cystic Artery Lymph Nodes.

Correspondence to: Kor Woi Tiang, Department of Surgery, Logan Hospital, Cnr Amstrong Rd \& Loganlea Rd, Meadowbrook, QLD 4131, Australia; Tel: +61452528789; E-mail: kor.tiang@uqconnect.edu.au

Key words: cystic artery lymph node, laparoscopic cholecystectomy, hepatobiliary triangle

Received: November 02, 2017; Accepted: November 24, 2017; Published: November 28, 2017 
significant morbidity and mortality [6]. The primary cause of BDI is due to misidentification of the hepatobiliary structures rather than patient (including clinical and demographic characteristics) or institutional factors $[7,8]$.

Connor et al. in 2014 proposed a standardized approach and checklist for LC, which included identification of cystic artery lymph node as an additional landmark to avoid BDI during LC. The article stated dissection of hepatobiliary triangle should be lateral to LN to minimize the risk of BDI [9]. Hepatobiliary (previously called Calot's) triangle in modern practice consists of the cystic duct as the inferior border, common hepatic duct as the medial border and inferior border of the liver as the superior border. The cystic artery lies within the triangle ( $82 \%$ in a recent review) [10]. Whilst identifying the cystic duct is mostly straightforward due to its continuity with the gallbladder neck (outdated infundibular technique), the cystic artery may be more difficult to identify [11]. The LN consistently lies superficial to the cystic artery and therefore lateral to the biliary tree. The LN was macroscopically intraoperatively identified in $53 \%$ of 300 LC [12]. The node was presumed absent in the remainder. The node was always on top of the cystic artery (i.e. superficial)-in 59\% it was anterior and in $41 \%$ behind the artery [12]. Multiple nodes were not identified. To our knowledge, this is the first description of three cystic artery lymph nodes.

\section{Conclusion}

We present the first patient with of three cystic artery lymph nodes. The frequency of multiple $\mathrm{LN}$ is unknown but does not impact on the surgical technique. Studies using pathology reports to identify whether the cystic artery LN was excised need to consider the presence of multiple nodes.

\section{Declarations}

No conflict of interest declared.

Ethics approval and consent to participate: The study patient has provided full informed consent regarding clinical information to be used in the write up of this article. It has been verified as true, appropriate and fit for publication by the patient and the authors. Further documentations may be requested if required by the journal.

Competing interests: No financial and non- financial competing interests have been declared.

Funding: No source of funding declared.
Authors' contributions: All 3 authors have made substantial contributions in the order listed on the paper to all the following: 1) conception and design of the study, review of available literature. 2) Drafting the article and revising it critically to comply with international standards, 3) Approval of the final version prior to submission.

Acknowledgements: The authors acknowledge the patient for allowing the write up of her clinical case for academic contribution. We greatly appreciate the consent given in this process.

\section{References}

1. Welfare AIoHa (2014) Elective surgery waiting times 2014-15: Australian hospital statistics: AIHW.

2. March B, Burnett D, Gani J (2016) Single-stage laparoscopic cholecystectomy and intraoperative endoscopic retrograde cholangiopancreatography: is this strategy feasible in Australia? ANZ J Surg 86: 874-877. [Crossref]

3. Ferzli G, Timoney M, Nazir S, Swedler D, Fingerhut A (2015) Importance of the node of Calot in gallbladder neck dissection: an important landmark in the standardized approach to the laparoscopic cholecystectomy. J Laparoendosc Adv Surg Tech A 25: 28-32. [Crossref]

4. Wysocki AP, Murphy S, Ware RS (2017) Is cystic artery lymph node excision during laparoscopic cholecystectomy a marker of technique? ANZ J Surg. In press. [Crossref]

5. Nassar AHM, Ashkar KA, Mohamed AY, Hafiz AA (1995) Is laparoscopic cholecystectomy possible without video technology? Minimally Invasive. Ther Allied Technol 4: 63-65.

6. Worth PJ, Kaur T, Diggs BS, Sheppard BC, Hunter JG, et al. (2016) Major bile duct injury requiring operative reconstruction after laparoscopic cholecystectomy: a followon study. Surg Endosc 30: 1839-1846. [Crossref]

7. Nuzzo G, Giuliante F, Giovannini I, Ardito F, D'Acapito F, et al. (2005) Bile duct injury during laparoscopic cholecystectomy: results of an Italian national survey on 56 591 cholecystectomies. Arch Surg140: 986-992. [Crossref]

8. Harrison VL, Dolan JP, Pham TH, Diggs BS, Greenstein AJ, et al. (2011) Bile duct injury after laparoscopic cholecystectomy in hospitals with and without surgical residency programs: is there a difference? Surg Endosc 25: 1969-1974. [Crossref]

9. Connor SJ, Perry W, Nathanson L, Hugh TB, Hugh TJ (2014) Using a standardized method for laparoscopic cholecystectomy to create a concept operation-specific checklist. $H P B$ (Oxford) 16: 422-429. [Crossref]

10. Andall RG, Matusz P, du Plessis M, Ward R, Tubbs RS, et al. (2016) The clinica anatomy of cystic artery variations: a review of over 9800 cases. Surg Radiol Anat 38: 529-539. [Crossref]

11. Ata AH (1991) Cystic artery identification during laparoscopic cholecystectomy. $J$ Laparoendosc Surg 1: 313-318. [Crossref]

12. Qamar N, Mirani AJ, Ahmad S, Parveen K, Sultan N (2014) Lymph node significance in cystic artery identification during Laparoscopic Cholecystectomy. Pakistan Journal of Surgery 30: 180-182.

Copyright: (C2017 Tiang KW. This is an open-access article distributed under the terms of the Creative Commons Attribution License, which permits unrestricted use, distribution, and reproduction in any medium, provided the original author and source are credited. 